
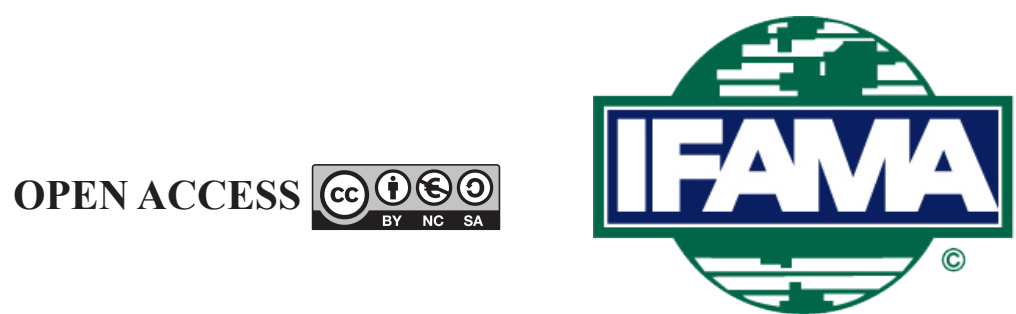

International Food and Agribusiness Management Review

Volume 24, Issue 5, 2021; DOI: 10.22434/IFAMR2020.0109

Received: 8 July 2020 / Accepted: 9 February 2021

\title{
Unlocking employee's green behavior in fertilizer industry: the role of green HRM practices and psychological ownership \\ RESEARCH ARTICLE
}

\author{
Muhammad Waqas ${ }^{\mathrm{a}, \mathrm{b}}$, Farzan Yahya ${ }^{\oplus \mathrm{b}}$, Ammar Ahmed $^{\mathrm{c}}$, Yasir Rasool ${ }^{\mathrm{d}}$ and Li Hongbo \\ ${ }^{a}$ Postdoctoral Research Fellow, ${ }^{e}$ Professor, School of Management, Jiangsu University, \\ 301 Xuefu Rd, Jingkou District, Zhenjiang, 212013, China P.R. \\ ${ }^{b}$ Assistant Professor, Department of Business Administration, Institute of Southern Punjab, \\ 9-KM, Bosan Road, Khayab-e-Yusuf, Multan, 66000, Pakistan \\ ${ }^{c}$ Assistant Professor, Department of Management Sciences, Muhammad Nawaz Sharif, University of \\ Engineering and Technology, Old Bahawalpur Road, Qasimpur Colony, Multan, 66000, Pakistan \\ ${ }^{d}$ Lecturer, Superior College, 31 Ferozepur Road, Kalma Chowk Flyover, \\ New Tipu Block Garden Town, Lahore, 54000, Pakistan
}

\begin{abstract}
The engineering of agrochemicals and inorganic fertilizers indirectly facilitates the emissions of $\mathrm{NO}_{2}$ and $\mathrm{CO}_{2}$. The extensive use of pesticides and inorganic chemical fertilizers has drawn the world's attention to green practices. Grounded on the ability-motivation-opportunity (AMO) theory, we investigated the effect of green human resource management (GHRM) practices on employees' green behavior with the mediating role of psychological ownership. We applied the partial least square structural equation modeling (PLS-SEM) technique to 279 responses acquired from the fertilizer manufacturing firm employees. The results show that GHRM practices (green competence building, green motivation enhancing, and green employee involvement practices) significantly improve employee green behavior. Additionally, GHRM practices enhance the sense of ownership of nature among employees due to which they involve themselves proactively in eco-friendly activities and behavior.
\end{abstract}

Keywords: employee green behavior, green HRM, psychological ownership, ability-motivation-opportunity theory, PLS-SEM

JEL code: N55, O15, Q13, Q15

\footnotetext{
(ํ) Corresponding author: farzan.yahya@yahoo.com
} 


\section{Introduction}

Realizing the protection of the planet for future generations, intergovernmental organizations are continuously developing policies to align 'green' with 'development' (Thore and Tarverdyan, 2016). Since agriculture is the backbone of many developing countries (Newman et al., 2020), this holds particularly for rebuilding natural capital by reducing agricultural greenhouse gas (GHG) emissions, biodiversity loss, decreasing deforestation, inorganic agrochemical pollution, and maintain soil fertility (Struik and Kuyper, 2017). Like other developing countries, Pakistan is also heavily dependent on the agriculture sector. Around $20 \%$ of the gross domestic product is contributed by the livestock and agriculture sector while $42 \%$ of the labor force is employed by the agricultural sector of Pakistan (Rehman et al., 2017). Nonetheless, environmental quality is largely compromised as the agriculture sector contributes a $40 \%$ share of GHG emissions primarily from the burning of crop residues, manure management, enteric fermentation, rice cultivation, soil management, and livestock which demands urgent consideration (Ullah et al., 2018).

Nitrogen $(\mathrm{N})$ and carbon dioxide $\left(\mathrm{CO}_{2}\right)$ are generally taken by crops from the soil and atmosphere which they reallocate to residues, soil organic matter, and living biomass. In cycle due to the combustion process, soil organic matter, biomass decomposition, and the respiration of the plants, toxic gases such as $\mathrm{NO}_{2}$, methane $\left(\mathrm{CH}_{4}\right)$, and $\mathrm{CO}_{2}$ are released to the atmosphere. Additionally, engineering of required inputs like agrochemicals and inorganic fertilizers also indirectly facilitate the emissions of $\mathrm{NO}_{2}$ and $\mathrm{CO}_{2}$ (Tripathi and Mishra, 2017). Thus, researchers believe that ecological catastrophes can be avoided by discouraging the use of pesticides and inorganic chemical fertilizers (Xu et al., 2015; Zhang et al., 2015). Nitrogen-rich fertilizers may form solid particles in the air with combustion emissions (Bauer et al., 2016). Although the use of fertilizers facilitates output growth, low-quality fertilizers are not safe for human consumption and have detrimental effects on soil fertility (Rahman and Zhang, 2018). Especially in the context of Pakistan, farmers have protested the shortage of several micronutrients in fertilizers that directly influence their crop production and soil fertility. Farmers' outrage encouraged Soil and Water Testing Laboratory for Research to test the samples of fertilizers. Ten out of eleven samples were found substandard (Dawn, 2020). This prominent issue motivates us to investigate if the greenness of the fertilizer industry can be improved by linking green human resource management (GHRM) practices to employee green behavior. The key elements of GHRM enhance a firm's sustainability by providing green opportunities, motivating pro-environmental behavior, and developing green ability in their employees (Renwick et al., 2013).

The contribution of an employee in environmental matters can be explained through the life cycle assessment (LCA) methodology that unravels the connection of environmental impacts with the entire production system (Russell et al., 2005). Since the employees are principal stakeholders of the production processes, they have assessable and more distinguishable social impact compared to other stakeholders (Mattioda et al., 2017). Their behavior is bound to affect the effective enactment of the firm's eco-friendly policies. In order to execute related practices efficiently, promoting environmental awareness in individual employees is crucial (Owino and Kwasira, 2016). The green HRM, defined as the set of systems, policies, and practices to develop a socially responsible, resource-efficient, and environmentally sensitive workplace is an efficient tool to encourage green employees' behavior. The green HRM practices (green competence building, green employee involvement, and green motivation enhancing practices) foster eco-friendly initiatives that result in sustainable development through the reduction of carbon footprint, better farming practices, and proper waste disposal (Jackson et al., 2011). Such green practices also play a vital role in managing brand equity and sustainable growth (Bombiak and Marciniuk-Kluska, 2018; Moise et al., 2019). However, the ultimate model to drive environmental performance cannot be developed without aligning the organizational green goals with employee behavior (Saeed et al., 2019). These concerns have highlighted the importance of the adoption of green HRM practices for better eco-friendly production processes. Accordingly, this study explains how GHRM practices lead to employees' green behavior by analyzing the mediating effect of psychological ownership (PO). Generally, researchers have associated psychological ownership with positive behavioral and attitudinal outcomes such as employee commitment, retention, job satisfaction, organizational citizenship behavior, and knowledge sharing (Degbey et al., in press; Pittino et al., 2018; Wang et al., 2019). Similarly, 
Matilainen et al. (2017) noted that ownership feelings may promote optimal use of natural resources under both cooperative and conflicting stakeholders' opinions. Here, we posit that GHRM practices build employees' green competency which boosts their feeling of possession over environmental concerns and motivates them to bring eco-friendly solutions.

Several key limitations in the existing literature led us to the design and rationale of this study. Based on the data collected from 279 employees associated with the fertilizer industry, this study extends the limited but rapidly growing body of research on employees' green behavior in several ways. First, prior studies have empirically investigated the effect of GHRM practices on employees' behavior in various sectors such as manufacturing small and medium enterprises (Singh et al., 2020), automobile industry (Yu et al., 2020), hospitality and tourism industry (Pham et al., 2019) but largely ignored the fertilizer sector. However, this study provides a better understanding of GHRM practices and employees' green behavior in the Agri industry in the context of a developing country like Pakistan. Since the field of GHRM is still in its infancy, consequently, this study directly answers the call (Dumont et al., 2017; Shafaei et al., 2020) for more extensive empirical evidence. Second, this study empirically tests GHRM practices separately derived from the ability-motivation-opportunity (AMO) framework which are so far tested by Anwar et al. (2020) on environmental performance through organizational citizenship behavior (OCB) in academics. Third, scant GHRM literature has considered individual-level employee engagement or behavior. However, employees may show less reluctance toward adopting eco-friendly behavioral facets when green policies or practices are adequately implemented (Unsworth et al., 2013). Thus, ignoring the behavioral aspects of employees may not provide a parsimonious model to proficiently improve a firm's sustainability. Studies suggest that HRM policies may influence employee behavior and outcomes through different aspects of psychological processes and called for incorporating certain mechanisms in the framework (Dumont et al., 2017; Renwick et al., 2013). Thus, introducing the mediating role of employee psychological ownership between green HRM and employee green behavior fills a major gap in the literature.

\section{Literature review and hypotheses development}

\subsection{Green competence building practices and psychological ownership}

The AMO theory substantially explains the role of GHRM and how the employee's ability, motivation, and opportunity contribute to organizational performance (Appelbaum et al., 2000; Renwick et al., 2013). The theory states that having relevant knowledge and skills by employees, continuous employer motivation, and provision of opportunities to the employees for participation in organizations' decision-making processes are conducive to smooth organizational operations. Thus, in order to achieve environmental sustainability, organizations should design efficient green HRM practices based on the AMO framework to align employees' behavior and attitudes with organizational green objectives (Dumont et al., 2017; Jia et al., 2018; Pham et al., 2019). Grounded on AMO perspective, Appelbaum et al. (2000) stated that the HRM practices that promote abilities, motivation, and opportunities of their employees and lead the organization to capture the mental and psychosomatic possession of its employees which further improves not only the performance of employees but also the performance of the organization. Organizations that demonstrate the wide application of GHRM practices get more benefits from their employees' productivity and efficiency (Salem et al., 2012)

In the light of the AMO model, several researchers have discussed the concept of Green HRM (GHRM) in multiple areas (Pham et al., 2019; Singh et al., 2020; Yu et al., 2020). For instance, Pham et al. (2019) noted that green education, green employee participation, and green functioning administration lead to organizational residency and employees' organizational citizenship behavior in the hospitality industry. Based on 126 automobile manufacturers in China, Yu et al. (2020) revealed that GHRM is positively related to environmental collaboration with clients and vendors while green supply chain management strengthens this association. Similarly, Singh et al. (2020) examined how green HRM practices interlink among green transformational leadership, green modernization, and ecological presentation in small and medium enterprises. Based on AMO theory and seminal work of Renwick et al. (2013), three major activities of GHRM are 
evaluated, i.e. green competence building practices (GCBP), green motivation enhancing practices (GMEP), and green employee involvement practices (GEIP).

The green competence building practices (GCBP) refer to green recruitment, selection, training, and development (T\&D) that improve employees' pro-environmental behavior through the green familiarity, recognition, branding, and criterion (Tang et al., 2018; Teixeira et al., 2012; Vidal-Salazar et al., 2012). The GCBP facilitates the environmental agenda of the organization by upskilling the employees in executing green working practices, instilling green values, and enhancing employees' environmental consciousness. The employers also give preference to those applicants who possess more diversified and compatible knowledge or skills to proactively deal with environmental issues within the organization (Tang et al., 2018). Developing green competencies of employees improve their sense of purpose and meaningfulness of work that makes them more psychologically available to tackle the environmental problems of the organizations. In line with these arguments, Pinzone et al. (2016) found the positive relationship of GCBP with collective organizational citizenship behaviors toward the environment. Similarly, Dumont et al. (2017) argued that green T\&D improves job-related and discretionary green behavior of employees.

Although studies have directly linked GHRM practices with employee's pro-environmental behavior (Harvey et al., 2013; Paillé et al., 2014), we believe that green T\&D or recruitment policies may enhance employee's psychological ownership, involves both shared beliefs and norms of behavior that are in line with the organization' best interest. Employees may take green initiatives when their targets are compactly associated with the self and extended self through the feeling of possession. Based on the AMO framework, Lu et al. (2017) found a positive effect of certain HRM practices on psychological ownership in Chinese small and medium-sized enterprises. Competence building of employees may help employees to intimately know their organizations. Based on their knowledge and skills, they share information frequently which enables them to familiarize, associate, and understand the organizational goals intimately (Huselid, 1995). This argument is also supported by other management theories (e.g. expectancy theory) that when employees will be recruited and trained on the green agenda, they will feel more proud once an organization's environmental goal is successfully fulfilled (Kim and Beehr, 2017). Accordingly, the following hypothesis is developed:

H1: Green competence building practices is positively related to psychological ownership.

\subsection{Green motivation enhancing practices and psychological ownership}

The green motivation practices emphasize the need for performance assessment and reward system. These practices align the employees' behavior towards the accomplishment of the organization's mission and goals (Harvey et al., 2013). In the case of firms' environment management, it must ensure that its employees clearly understand the environment of the organization. By providing regular feedback regarding environmental performance, the skills, professional approach, efficiency, and productivity of employees in environmental management can be improved (Jackson et al., 2011). Daily and Huang (2001) documented that rewards based on environmental performance improves employees' commitment and make them more environmentally responsible.

A previous study by Milkovich and Wigdor (1991) argued that performance-contingent rewards motivate employees to invest the self into organizational goals. Appraising performance and rewarding employees on the basis of their connection with environmental performance, incentives for recycling, proposing solutions to mitigate emissions, using pollution-free conveyance may act as positive reinforcement (Jackson et al., 2011). This reward and assessment system may create a win-win situation and individuals may experience a cognitive-affective state (i.e. psychological ownership, where they own the responsibilities for achieving success (Degbey et al., in press). In light of the aforementioned arguments, we have built the following hypothesis:

H2: Green motivation enhancing practices is positively related to psychological ownership. 


\subsection{Green employee involvement practices and psychological ownership}

Organizations with green practices provide equal opportunities to their employees in the decision-making process (DuBois and Dubois, 2012) which makes them feel empowered. Employee empowerment leads to self-control and improves their problem-solving skills (Renwick et al., 2013). When the employees are involved in decision-making, it leads to an establishment of pro-environmental culture in the firms and supports the free exchange of knowledge and ideas at the desired levels (Alt and Spitzeck, 2016). Firms that encourage their employees to become a part of the decision-making process, help them to develop a positive attitude of psychological ownership (Liu et al., 2012). The enriched autonomy related to selfmanaging work teams stimulates the feeling of possession (Pierce et al., 2003). Employees who can control the work are more likely to be aroused to work in the best interests of the organization (Lu et al., 2017). The theory of psychological ownership strongly supports the notion that empowering employees may make them more responsible, protective, and attached to the organizational goals (Van Dyne and Pierce, 2004). Thus, we believe that GEIP enhances psychological ownership by empowering and engaging the workforce to recommend green policies and execute them confidently (Haddock-Millar et al., 2016). Accordingly, the subsequent hypothesis is recommended:

H3: Green employee involvement practices is positively related to psychological ownership.

\subsection{Psychological ownership and employee green behavior}

Psychological ownership plays a vital role in developing certain attitudes and behaviors of the employees, thus, the environment of organizations is highly founded on psychological rather than legal or real ownership (Jackson et al., 2011; Pierce et al., 2003). For instance, employees may have developed a sense of ownership for their working organizations despite the absence of any equity in it (Van Dyne and Pierce, 2004). In the organizational settings, an increased level of psychological ownership leads to higher commitment and loyalty (Han et al., 2010) and employees' stewardship behavior (Avey et al., 2009). The sense of ownership also positively influences employees' efforts towards achieving the organizational objectives and develop their proenvironmental attitudes (Jussila et al., 2015; Kamleitner and Rabinovich, 2010). Furthermore, psychological ownership makes them (employees) understand their roles and responsibilities within the organization. It also leads to their citizenship behavior (Anwar et al., 2020; Poutsma et al., 2015), and extra-role behavior (Mustafa et al., 2015), including employee green behavior (Dumont et al., 2017). Süssenbach and Kamleitner (2018) argued that psychological ownership is an effective tool that may stimulate pro-environmental behavior and combat systematic obstacles to sustainable development. Although the empirical link between PO and employee green behavior (EGB) is developed in previous literature, it is still underexplored especially in the context of the fertilizer industry's employees. Based on the above-mentioned argument, the following hypothesis is expressed:

H4: Psychological ownership is positively related to employee green behavior.

\subsection{The intervening role of psychological ownership}

The developmental HRM literature identifies that HR practices may not directly have an emotional impact on employee behavior; rather, effects are transferred through various underlying mechanisms (Jiang et al., 2012). In this study, it is proposed that psychological ownership is a psychological process through which green HRM practices influence EGB. The AMO-based GHRM practices develop meaningfulness of work along with the sense of familiarity and knowledge of the organization which in turn develop psychological ownership. Likewise, more control over their work through GHRM boosts employee's work autonomy and self-efficacy (Pierce et al., 2003). When employees feel psychological ownership, they consider the organizational identity as their extended self and thereby, thrive to achieve the organization's environmental and sustainable goals (Jiang and $\mathrm{Li}$, 2019). Through accountability, self-identity, belongingness, and self-efficacy, PO involves employees to take more initiative in citizenship behavior toward the environment (Wang et al., 2019). 
Prior studies have utilized PO as an alignment mechanism between positive leadership and employees' extrarole behaviors (Kim and Beehr, 2017), transformational leadership and employee engagement (Ghafoor et al., 2011), ethical leadership and job satisfaction (Avey et al., 2012), material values and pro-environmental behaviors (Felix and Almaguer, 2019) and between empowered leadership and OCB toward the environment (Jiang and Li, 2019). Grounded on psychological ownership and AMO theory, we hypothesized that green HRM practices trigger green behavior of employees by enhancing their psychological ownership toward the environment and eco-friendly organizational policies:

H5: Psychological ownership mediates the relationship between green competence building practices and employee green behavior.

H6: Psychological ownership mediates the relationship between green motivation enhancing practices and employee green behavior.

H7: Psychological ownership mediates the relationship between green employee involvement practices and employee green behavior.

\section{Methods}

\subsection{Data collection and sampling}

The respondents of the study were associated with the fertilizer sector of Pakistan and only those fertilizer manufacturing companies were taken as samples that were ISO 14000 certified. ${ }^{1}$ Discussion with higher management revealed that these companies were engaged in environmental management and green HR practices. Before the distribution of the questionnaires, approval was taken from the respective higher management. The objective of the study and the confidentiality of the responses were explained to the respondents. Survey questionnaires were distributed during the working hours. Respondents were allowed to fill the questionnaire voluntarily and can return it without filling it. Questionnaires were returned during the working hours in the presence of their supervisors and managers.

Keeping in mind the time and budget constraints, the data were collected through the convenience sampling technique. ${ }^{2}$ For estimating appropriate sample size, we have utilized $G^{*}$ Power software (Heinrich-HeineUniversität, Düsseldorf, Germany) ('a priori' power analysis) suggested by Hair et al. (2017). This analysis recommended a minimum sample size of 138 for a statistical power of $80 \%$ in terms of 0.15 effect size and four predictors. However, we distributed 400 questionnaires for this study. The targeted employees were working in four different companies situated in different provinces of Pakistan. Therefore, we believe that a sample of 400 respondents is adequate for the study. The questionnaires were returned by 296 respondents but 279 were retained after discarding missing and improper responses. The response rate for this study was $69.5 \%$. Around $73.4 \%$ of the respondents were male and $26.6 \%$ were female, the highest percentage (i.e. 54.2\%) of the respondents were within the age bracket of 31 to 35 years, most of the respondents (i.e. $66.8 \%$ ) had at least master's degree, $48 \%$ of the respondents were highly experienced (served between 5 to 10 years in the fertilizer industry) and $23 \%$ of the individuals are employed in the same organization from last 10 years.

\footnotetext{
${ }^{1}$ Although there are six ISO 14000 certified fertilizer firms in Pakistan, we were able to collect data from four companies, i.e. Fauji Fertilizer, Engro Fertilizer Company, Dawood Hercules, and Fatima Fertilizers

${ }^{2}$ Although convenience sampling is criticized by the researcher due to its inability to produce representative results, we used this technique due to limited population of the study. There are only six fertilizer companies in Pakistan with ISO 14000 certification from which two companies did not respond positively toward the survey. For rest of the firms, we were able to collect the data from the employees referred by the management. Nonetheless, we have tried to reduce several statistical biases (e.g. CMV or measurement error) to produce representative estimates.
} 


\subsection{Measures}

Measures used in this study were adopted from the existing literature. All the responses were recorded on a five-point Likert scale ranging from $1=$ strongly disagree to $5=$ strongly agree. The theoretical framework contained three exogenous constructs, two of them were green competence building practices (GCBP) and green motivation enhancing practices (GMEP) which were reflective-reflective. GCBP was a higher-order construct (HOC) whereas green recruitment and selection (GRS) and green training (GT) was its lowerorder constructs (LOCs). Similarly, GMEP was HOC whereas green performance and management (GPM) and green pay and reward (GPR) were LOCs. Green employee involvement practices (GEIP) were a third and lower order construct. These three constructs were measured by using a 19-items scale by Tang et al. (2018). The reliability coefficient of all their constructs was above 0.7 . A sample question includes 'we develop training programs in environmental management to increase environmental awareness, skills, and expertise of employees'. We found Cronbach alpha and composite reliability of all the constructs above 0.80 ensuring the scale's reliability.

Psychological ownership was measured by using five items scale by Pierce et al. (1991). An example of an item was 'I am comfortable being in this organization'. Cronbach's alpha value was 0.870 , and composite reliability of 0.918. Employee green behavior was measured by using five items from Pierce et al. (1991). A sample item was 'At work, I take part in environmentally friendly programs'. Cronbach's alpha value was 0.73 .

\subsection{Common method variance bias}

Common method variance (CMV) was addressed using Harman single factor analysis (Harman, 1967) because data were collected from a single source (Podsakoff et al., 2003). Exploratory factor analysis showed the first factor explained 30.494 variances suggesting CMV was not an issue (Babin et al., 2016).

\subsection{Statistical analysis}

Recent studies relevant to green HRM have used Smart PLS (Anwar et al., 2020; Fernando et al., 2019; Pham et al., 2019). The partial least square structural equation modeling (PLS-SEM) approach using Smart PLS 3.2.8 (SmartPLS GmbH, Bönningstedt, Germany) was utilized for data analysis. The PLS-SEM can deal with complex mediation models (Hair et al., 2019), and it does not assume strict normality (Chin et al., 2003). Following the guidelines provided by previous studies (Ramayah et al., 2018), in the first stage, the measurement model of the LOCs was reported. Latent Variable Scores were saved and copied to the original data file. These latent variables served as indicators of the HOCs (GCBP and GMEP). In the second stage, the measurement model of the HOCs and structural model were reported.

\section{- Measurement model}

The measurement model was evaluated by outer loadings, average variance extracted (AVE), composite reliability (CR), heterotrait-monotrait (HTMT) criterion. These tests were used to assess convergent validity (CV), internal consistency reliability, and discriminant validity (DV) respectively. Factor loadings and AVE should be equal to or greater than 0.50. CR should be equal to or greater than 0.70 and HTMT value should not exceed 0.90 (Franke and Sarstedt, 2019). It can be seen from Table 1 that all AVE values were above 0.50 , CR was greater than 0.70 for all constructs, outer loadings were above 0.50 . However, GPR1 was removed in the first stage to bring the results in the acceptable range. HTMT criteria showed that all values were less than 0.90 . Therefore, all the criteria requirements of the measurement model for the first stage were fulfilled. 
Table 1. Reliability and validity of the first order constructs. ${ }^{1}$

\begin{tabular}{|c|c|c|c|}
\hline Constructs and items & Factor loadings & $\begin{array}{l}\text { Composite } \\
\text { reliability }\end{array}$ & $\begin{array}{l}\text { Average variance } \\
\text { extracted }\end{array}$ \\
\hline Green recruitment and selections (GRS) & & 0.813 & 0.594 \\
\hline GRS1 & 0.770 & & \\
\hline GRS2 & 0.863 & & \\
\hline GRS3 & 0.667 & & \\
\hline Green training $(\mathrm{GT})$ & & 0.855 & 0.664 \\
\hline GT1 & 0.800 & & \\
\hline GT2 & 0.906 & & \\
\hline GT3 & 0.729 & & \\
\hline Green pay and reward (GPR) & & 0.773 & 0.632 \\
\hline GPR2 & 0.869 & & \\
\hline GPR3 & 0.714 & & \\
\hline Green performance management (GPM) & & 0.890 & 0.669 \\
\hline GPM1 & 0.807 & & \\
\hline GPM2 & 0.809 & & \\
\hline GPM3 & 0.867 & & \\
\hline GPM4 & 0.786 & & \\
\hline Green employee involvement practices (GEIP) & & 0.837 & 0.510 \\
\hline GEIP1 & 0.745 & & \\
\hline GEIP2 & 0.790 & & \\
\hline GEIP3 & 0.594 & & \\
\hline GEIP4 & 0.765 & & \\
\hline GEIP5 & 0.658 & & \\
\hline Psychological ownership (PO) & & 0.895 & 0.632 \\
\hline $\mathrm{PO} 1$ & 0.850 & & \\
\hline $\mathrm{PO} 2$ & 0.797 & & \\
\hline PO3 & 0.824 & & \\
\hline PO4 & 0.684 & & \\
\hline PO5 & 0.808 & & \\
\hline Employee green behavior (EGB) & & 0.838 & 0.563 \\
\hline EGB1 & 0.763 & & \\
\hline EGB2 & 0.732 & & \\
\hline EGB3 & 0.788 & & \\
\hline EGB4 & 0.718 & & \\
\hline
\end{tabular}

Similarly, the measurement model for second-order constructs was evaluated using the same criteria. It can be noticed from Table 2 that all AVE and CR values were within the acceptable range. EGB1, EGB3, and EGB5 were deleted due to low outer loadings. HTMT correlation value between GMEP and GCBP was very close to 0.90 as shown in Table 3. However, items or LOCs could not be removed from the model because they were considered a necessary part of HOC. Therefore, LOCs with higher correlation values were retained. 
Table 2. Reliability and validity of the second-order constructs.

\begin{tabular}{llll}
\hline Constructs and items & Factor loadings & $\begin{array}{l}\text { Composite } \\
\text { reliability }\end{array}$ & $\begin{array}{l}\text { Average variance } \\
\text { extracted }\end{array}$ \\
\hline Green competence building practices (GCBP) & & 0.800 & 0.669 \\
GCBP1 & 0.892 & & \\
GCBP2 & 0.736 & 0.806 & 0.676 \\
Green motivation enhancing practices (GMEP) & & & \\
GMEP1 & 0.881 & 0.510 \\
GMEP2 & 0.759 & \\
Green employee involvement practices (GEIP) & & & \\
GEIP1 & 0.745 & \\
GEIP2 & 0.791 & \\
GEIP3 & 0.594 & & \\
GEIP4 & 0.764 & & \\
GEIP5 & 0.658 & & \\
Psychological ownership (PO) & & & \\
PO1 & 0.852 & 0.895 & \\
PO2 & 0.793 & & \\
PO3 & 0.824 & & \\
PO4 & 0.686 & & \\
PO5 & 0.810 & & \\
Employee green behavior (EGB) & & & \\
EGB2 & 0.733 & 0.815 & \\
EGB4 & 0.919 & & \\
\hline
\end{tabular}

Table 3. Discriminant validity of the second-order constructs. ${ }^{1}$

\begin{tabular}{|c|c|c|c|c|c|}
\hline Constructs & EGB & GCBP & GEIP & GMEP & PO \\
\hline \multicolumn{6}{|l|}{ EGB } \\
\hline GCBP & 0.806 & & & & \\
\hline GEIP & 0.637 & 0.855 & & & \\
\hline GMEP & 0.782 & 0.898 & 0.782 & & \\
\hline PO & 0.653 & 0.816 & 0.601 & 0.684 & \\
\hline
\end{tabular}

\section{- Structural model}

According to guidelines provided by Ramayah et al. (2018) and Hair et al. (2017), the structural model was assessed, using 5,000 resample for bootstrapping technique. Multi-collinearity was assessed through the variance inflation factor (VIF) values. Diamantopoulos and Siguaw (2006) suggested that the VIF value should be less than 3.3. All values were below 3.3 for all relationships ensuring no issue of multi-collinearity. Predictive relevance $\left(\mathrm{Q}^{2}\right)$ was evaluated using the blindfolding procedure (Geisser, 1975). $\mathrm{Q}^{2}$ value greater than zero indicates the presence of a model's predictive relevance (Sinkovics et al., 2016). $\mathrm{Q}^{2}$ values of two endogenous constructs (PO and EGB) were 0.237 and 0.147 indicating sufficient predictive relevance of the model. Effect sizes $\left(\mathrm{f}^{2}\right)$ were evaluated for all relationships. According to Cohen (1992), 0.02, 0.15, and 0.35 represent small, medium, and large effects respectively. GCBP, GEIP, and GMEP had a medium effect on $\mathrm{PO}$, and $\mathrm{PO}$ had a large effect on EGB respectively. 


\section{Results}

The results show that all GHRM practices are positively and significantly associated with PO. Thus, we accept the first three hypothesis that GCBP $(\beta=0.330, t=4.832, \mathrm{LL}=0.195, \mathrm{UL}=0.460), \mathrm{GEIP}(\beta=0.223$, $t=3.072, \mathrm{LL}=0.074, \mathrm{UL}=0.359)$ and $\operatorname{GMEP}(\beta=0.184, t=2.711, \mathrm{LL}=0.047, \mathrm{UL}=0.310)$ have a positive effect on PO. The three predictors explained $38.7 \%$ of the variance in PO which is satisfactory as per the above $10 \%$ criteria of Falk and Miller (1992). The results of the direct effects also show a positive and significant association of PO with EGB ( $\beta=0.485, t=9.861, \mathrm{LL}=0.376, \mathrm{UL}=0.573)$, leading to the acceptance of the fourth hypothesis (Table 4). Additionally, $\mathrm{R}^{2}$ was 0.235 explaining a $23.5 \%$ variance in EGB by PO.

We follow the criteria of Preacher and Hayes (2004) for the mediation analysis (indirect effects). A statistically significant indirect effect (two tail) with $t$-value equal to or greater than 1.96 and $P$-value equal to or less than 0.05 was considered for mediation to exist (Memon et al., 2018). PO mediated between GCBP and $\operatorname{EGB}(\beta=0.160, t=3.906, \mathrm{LL}=0.084, \mathrm{UL}=0.243)$, GEIP and $\mathrm{EGB}(\beta=0.108, t=2.809, \mathrm{LL}=0.034, \mathrm{UL}=0.184)$, and between GMEP and EGB $(\beta=0.089, t=2.594, \mathrm{LL}=0.023, \mathrm{UL}=0.157)$. Thus, $\mathrm{H} 5, \mathrm{H} 6$ and $\mathrm{H} 7$ were also supported. The details of indirect effects are presented in Table 5. A more comprehensive overview of the results is given in Figure 1.

Table 4. Direct effects. ${ }^{1}$

\begin{tabular}{llllllllll}
\hline Hypothesis & Relationships & S. Beta & S.D. & $\boldsymbol{t}$-value & $\boldsymbol{P}$-value & BCI LL & BCI UL & $\mathbf{f}^{2}$ & VIF \\
\hline H1 & GCBP $\rightarrow$ PO & 0.330 & 0.068 & 4.832 & 0.000 & 0.195 & 0.460 & 0.104 & 1.705 \\
H2 & GEIP $\rightarrow$ PO & 0.223 & 0.073 & 3.072 & 0.002 & 0.074 & 0.359 & 0.047 & 1.742 \\
H3 & GMEP $\rightarrow$ PO & 0.184 & 0.068 & 2.711 & 0.007 & 0.047 & 0.310 & 0.036 & 1.520 \\
H4 & PO $\rightarrow$ EGB & 0.485 & 0.049 & 9.861 & 0.000 & 0.376 & 0.573 & 0.307 & 1.000 \\
\hline
\end{tabular}

${ }^{1} \mathrm{BCI}=$ bias confidence interval; $\mathrm{f}^{2}=$ effect size; $\mathrm{LL}=$ lower limit; S. Beta $=$ standardized Beta; S.D. $=$ standard deviation; $\mathrm{UL}=$ upper limit; VIF $=$ variance inflation factor.

Table 5. Indirect effects. ${ }^{1}$

\begin{tabular}{llllllll}
\hline Hypothesis & Relationships & S. Beta & S.D. & $\boldsymbol{t}$-value & $\boldsymbol{P}$-value & BCI LL & BCI UL \\
\hline H5 & GCBP $\rightarrow$ PO $\rightarrow$ EGB & 0.160 & 0.041 & 3.906 & 0.000 & 0.084 & 0.243 \\
H6 & GEIP $\rightarrow$ PO $\rightarrow$ EGB & 0.108 & 0.039 & 2.809 & 0.005 & 0.034 & 0.184 \\
H7 & GMEP $\rightarrow$ PO $\rightarrow$ EGB & 0.089 & 0.034 & 2.594 & 0.010 & 0.023 & 0.157 \\
\hline
\end{tabular}

${ }^{1} \mathrm{BCI}=$ bias confidence interval; $\mathrm{LL}=$ lower limit; S. Beta $=$ standardized Beta; S.D. $=$ standard deviation; UL $=$ upper limit.

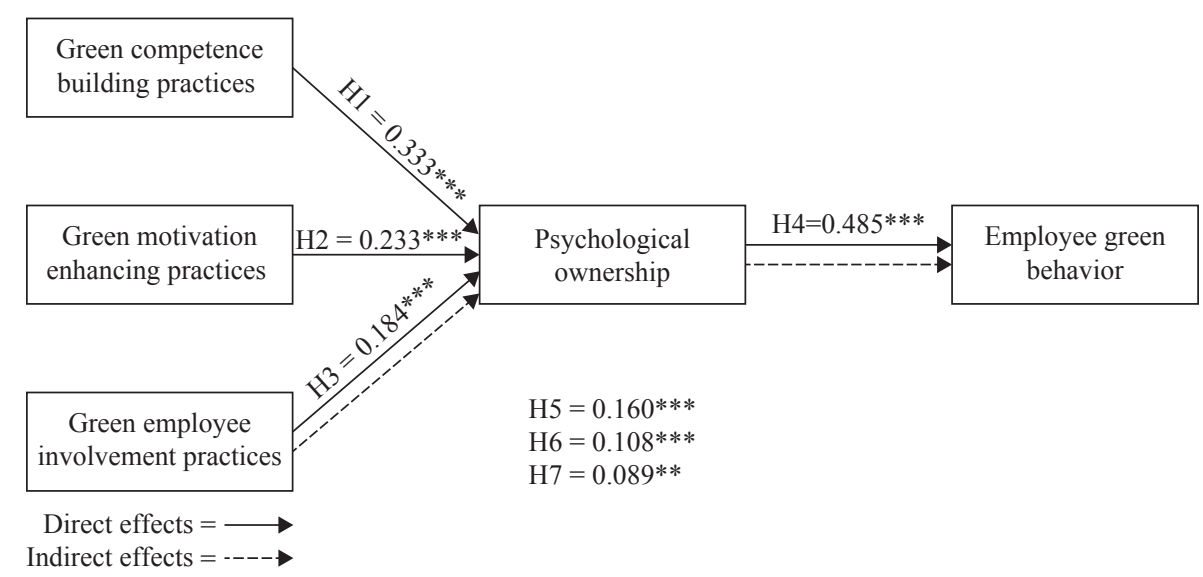

Figure 1. Mediational model of psychological ownership in the relationship between green HRM and green employee behavior $* * P<0.05, * * * P<0.01$. 


\section{Discussion}

The current study sheds light on green HRM practices which are an emerging area of interest among researchers and practitioners. This study is the first attempt that provided insights into the green practices and behavioral mantra of the fertilizer industry of Pakistan. Nitrogen-rich and phosphate fertilizer industry are the major source of the ambient level of hazardous air pollutants and soil pollution (Bauer et al., 2016; Kassir et al., 2012; Li et al., 2015). Thus, implementing eco-friendly policies and stimulating employee behavior toward green products may improve the environmental performance of the industry. Although a wide range of studies have underpinned the AMO theory to explain the mechanisms through which green HRM executes pro-environmental behavior in the organization (e.g. Jia et al., 2018; Renwick et al., 2013; Yu et al., 2020), little has been explored in the context of a comprehensive AMO framework. We extended the theoretical contributions by introducing the mediating role of psychological ownership between green HRM practices and employee green behavior.

Our findings suggest that the underlying parsimonious framework can be implemented to stimulate individual green behavior in an organization. The findings suggest green competence building practices that include green training, recruitment, and selection develop psychological ownership of the environment among employees through which they behave in an eco-friendly manner. Consistent with prior studies, we argue that when employers recruit employees based on green criteria or green awareness, the more likely they thrive to reduce environmental risks (Yong et al., 2020). In the same way, building green competency in an employee through adequate training and development boost their complementary role to bring environmentally friendly solutions (Anwar et al., 2020) against mineral depletion, acidification of the soil, air pollution, crop burning methods, and waterway pollution. Thus, green recruitment and training of employees enhance their interdependent self-construal focus toward societal well-being and they psychologically own the environmental concerns of their firm (Felix and Almaguer, 2019; Wang et al., 2019).

Our results also suggest that psychological ownership mediates the relationship between green motivation enhancing practices and employee green behavior. Rewarding and appraising employees may help organizations to develop certain mechanisms (such as psychological ownership) that mitigate systematic barriers to sustainability and environmental performance (Süssenbach and Kamleitner, 2018). Green motivating enhancing practices excite individuals to achieve environmental goals through different routes of psychological ownership including investing, gaining knowledge, and controlling environmental issues (Pierce et al., 2001). A reward system is an effective mechanism to foster employee engagement through psychological functioning (Presbitero, 2017; Renwick et al., 2013). Since psychological ownership enhance the satisfaction of rewards (Dawkins et al., 2017), voluntary environmental behavior of employees can be developed when systematic rewards for environmental initiatives are offered.

The findings also revealed that green employee involvement practices significantly affect employee green behavior through psychological ownership. The sense of psychological ownership can be boosted if employees are encouraged to actively participate in certain decisions and activities (Lu et al., 2017). Greater involvement and participation of employees may enhance their sense of empowerment, opportunity, and ownership that satisfy their humanistic needs (Han et al., 2010). Consequently, employees align their interests to the organization's green goals by opting for voluntary eco-friendly behavior and proactively involving themselves in knowledge sharing, idea exchanging, and open discussion to deal with environmental issues (Alt and Spitzeck, 2016; Hameed et al., 2020).

Besides theoretical contributions, the findings of the study also provide practical implications. While prior studies consider different industries (Anwar et al., 2020; Pham et al., 2019; Pinzone et al., 2016; Singh et al., 2020; Yu et al., 2020), we apply an AMO-based framework to the fertilizer industry. In this instance, Pakistan is facing severe environmental issues including desertification, natural disasters, soil erosion, pesticide misuse, climate change, noise pollution, and air pollution. Nutrients, pesticides, animal wastes, and sediment are primary agricultural pollutants. Hazardous pesticides may contaminate ground-water resources 
and surfaces while the fumes from nitrogen and phosphorus cause air pollutant emissions (Bauer et al., 2016; Hussain et al., 2017; Ullah et al., 2018). Thus, implementing green practices, policies, and indulging employees in pro-environmental behavior is very important for the fertilizer industry.

While recruiting and selecting employees for the firm, employers should ask about innovative ideas to reduce environmental issues caused by the fertilizer industry. Attracting employees with an eco-friendly approach may enhance the organization's environmental innovation and eventually, motivate employees to propose methods to produce environmentally friendly fertilizers. For instance, coating the fertilizers in a natural substance (chitosan, wheat, starch, etc.) may prevent the fertilizers from being delivered all at once. Training and involving employees based on green agenda may also motivate them to explore approaches to avoid the wastage of micronutrients which is one of the main causes of malnutrition in developing countries. Furthermore, continuous training, rewarding, and involvement of employees in pro-environmental activities can enhance their psychological ownership of nature through which they may go beyond their prescribed job responsibilities to develop products or solutions that resolve the issues of waterway pollution and algae bloom caused by excess nutrients from the fertilizers.

\subsection{Limitation and future research}

This study is not beyond certain limitations which should be accounted for by future studies. We utilized a cross-sectional method and single-source data. Future studies should use a multi-source, longitudinal, and multi-wave approach to provide more robust estimates. Researchers may also focus on other sectors to enhance the generalization of the results using other mediating factors. One of the major limitations of this study is the consideration of only positive aspects of psychological ownership. Future studies should also incorporate the negative effects of psychological ownership such as resistance to change, rejection of new knowledge, and reluctance to share knowledge and ideas with co-workers (Baer and Brown, 2012). A recent study by Cocieru et al. (2019) argued that when an organizational representative imposes revolutionary and subtractive changes on the project which is psychologically owned by the employees, negative emotions such as intentions to resist change and decreased level of affective commitment to change may emerge. Furthermore, negative reactions to changes namely the need for control and recipient narcissism caused by excessive psychological ownership may have detrimental effects on organizational functions. Since PO has a 'double-edged sword' effect in organizations, future studies are suggested to estimate if the relationship between PO and employee behavior is curvilinear.

\section{Conclusions}

Public awareness of environmental degradation is forcing firms to adopt clean practices and technologies. In the face of stakeholder outrage and consumer attitude toward green products, the fertilizer industry cannot achieve long-term sustainability without environmental initiatives and green practices. We contribute to the limited literature on the relationship between green HRM practices and employee pro-environmental behavior. Our results suggest that green HRM practices (ability building, motivation enhancing, and opportunity providing) develop a sense of ownership of nature among employees through which they behave and act in an eco-friendly way. The findings provide fruitful insights to policymakers for enhancing the green behavior of employees through recruitment, selection, training, empowerment, involvement, and the provision of opportunities.

The food and agriculture sectors generate both environmental harm and conserve ecosystem services. This is because these sectors both depend on and impact natural resources (land, water, and biodiversity) in the production process. The pressure on natural resources, climate change, and the recent economic crisis have highlighted the need for a greener model of growth. Green growth is the pursuit of economic growth and development while preventing environmental degradation, biodiversity loss, and unsustainable natural resource use. There is considerable interest in understanding the contribution of the agriculture sector to green growth, and the role of policies in moving towards a greener growth model. The implications of green 
growth for agriculture and the contributions of agriculture to green growth can be reciprocal or incongruent. In the short-term, green growth policies which place a premium on environmental protection may constrain agricultural output, reduce global food supply and entail adjustments in the use of human, financial, and natural resources. Adaptation measures may be helpful in the transition towards green growth. But the implications of green growth for agriculture and the food system in the longer-term should be mutuallyreinforcing in terms of environmental sustainability (including avoiding resource depletion), economic growth, and social well-being.

\section{References}

Alt, E. and H. Spitzeck. 2016. Improving environmental performance through unit-level organizational citizenship behaviors for the environment: a capability perspective. Journal of Environmental Management 182: 48-58.

Anwar, N., N.H.N. Mahmood, M.Y. Yusliza, T. Ramayah, J.N. Faezah and W. Khalid. 2020. Green human resource management for organisational citizenship behaviour towards the environment and environmental performance on a university campus. Journal of Cleaner Production 256: 120401.

Appelbaum, E., T. Bailey, P. Berg, A.L. Kalleberg and T.A. Bailey. 2000. Manufacturing advantage: why high-performance work systems pay off. Cornell University Press, Ithaca NY, USA.

Avey, J.B., B.J. Avolio, C.D. Crossley and F. Luthans. 2009. Psychological ownership: theoretical extensions, measurement and relation to work outcomes. Journal of Organizational Behavior: The International Journal of Industrial, Occupational and Organizational Psychology and Behavior 30(2): 173-191.

Avey, J.B., T.S. Wernsing, and M.E. Palanski. 2012. Exploring the process of ethical leadership: the mediating role of employee voice and psychological ownership. Journal of Business Ethics 107(1): 21-34.

Babin, B.J., M. Griffin and J.F. Hair Jr. 2016. Heresies and sacred cows in scholarly marketing publications. Journal of Business Research 69(8): 3133-3138..

Baer, M. and G. Brown. 2012. Blind in one eye: how psychological ownership of ideas affects the types of suggestions people adopt. Organizational Behavior and Human Decision Processes 118(1): 60-71.

Bauer, S.E., K. Tsigaridis and R. Miller. 2016. Significant atmospheric aerosol pollution caused by world food cultivation. Geophysical Research Letters 43(10): 5394-5400.

Bombiak, E. and A. Marciniuk-Kluska. 2018. Green human resource management as a tool for the sustainable development of enterprises: Polish young company experience. Sustainability 10(6): 1739.

Chin, W.W., B.L. Marcolin and P.R. Newsted. 2003. A partial least squares latent variable modeling approach for measuring interaction effects: results from a Monte Carlo simulation study and an electronic-mail emotion/adoption study. Information Systems Research 14(2): 189-217.

Cocieru, O.C., M.C. Lyle, L.C. Hindman and M.A. McDonald. 2019. The 'dark side'of psychological ownership during times of change. Journal of Change Management 19(4): 266-282.

Cohen, J. 1992. Quantitative methods in psychology: a power primer. Psychological Bulletin 112(1): 155-159.

Daily, B.F. and S.C. Huang. 2001. Achieving sustainability through attention to human resource factors in environmental management. International Journal of Operations \& Production Management 21(12): 1539-1552.

Dawkins, S., A.W. Tian, A. Newman and A. Martin. 2017. Psychological ownership: a review and research agenda. Journal of Organizational Behavior 38(2): 163-183.

Dawn. 2020. Lab test finds fertilisers substandard. Dawn, October 22, 2020. Available at: https://www. dawn.com/news/574523

Degbey, W.Y., P. Rodgers, M.D. Kromah and Y. Weber. in press. The impact of psychological ownership on employee retention in mergers and acquisitions. Human Resource Management Review. https:// doi.org/10.1016/j.hrmr.2020.100745

Diamantopoulos, A. and J.A. Siguaw. 2006. Formative versus reflective indicators in organizational measure development: a comparison and empirical illustration. British Journal of Management 17(4): 263-282.

DuBois, C.L. and D.A. Dubois. 2012. Strategic HRM as social design for environmental sustainability in organization. Human Resource Management 51(6): 799-826. 
Dumont, J., J. Shen and X. Deng. 2017. Effects of green HRM practices on employee workplace green behavior: the role of psychological green climate and employee green values. Human Resource Management 56(4): 613-627.

Falk, R.F. and N.B. Miller. 1992. A primer for soft modeling. University of Akron Press, Akron, OH, USA.

Felix, R. and J. Almaguer. 2019. Nourish what you own: psychological ownership, materialism and proenvironmental behavioral intentions. Journal of Consumer Marketing 36(1): 82-91.

Fernando, Y., C.J.C. Jabbour and W.X. Wah. 2019. Pursuing green growth in technology firms through the connections between environmental innovation and sustainable business performance: does service capability matter? Resources, Conservation and Recycling 141: 8-20.

Franke, G. and M. Sarstedt. 2019. Heuristics versus statistics in discriminant validity testing: a comparison of four procedures. Internet Research 29(3): 430-447.

Geisser, S. 1975. The predictive sample reuse method with applications. Journal of the American Statistical Association 70(350): 320-328.

Ghafoor, A., T.M. Qureshi, M.A. Khan and S.T. Hijazi. 2011. Transformational leadership, employee engagement and performance: mediating effect of psychological ownership. African Journal of Business Management 5(17): 7391-7403.

Hair, J., C.L. Hollingsworth, A.B. Randolph and A.Y.L. Chong. 2017. An updated and expanded assessment of PLS-SEM in information systems research. Industrial Management \& Data Systems 117(3): 442-458.

Hair, J.F., J.J. Risher, M. Sarstedt and C.M. Ringle. 2019. When to use and how to report the results of PLSSEM. European Business Review 31(1): 2-24.

Haddock-Millar, J., C. Sanyal and M. Müller-Camen. 2016. Green human resource management: a comparative qualitative case study of a United States multinational corporation. The International Journal of Human Resource Management 27(2): 192-211.

Hameed, Z., I.U. Khan, T. Islam, Z. Sheikh and R.M. Naeem. 2020. Do green HRM practices influence employees' environmental performance? International Journal of Manpower 41(7): 1061-1079.

Han, T.-S., H.-H. Chiang and A. Chang. 2010. Employee participation in decision making, psychological ownership and knowledge sharing: mediating role of organizational commitment in Taiwanese hightech organizations. The International Journal of Human Resource Management 21(12): 2218-2233.

Harman, D., 1967. A single factor test of common method variance. Journal of Psychology 35: 359-378.

Harvey, G., K. Williams and J. Probert. 2013. Greening the airline pilot: HRM and the green performance of airlines in the UK. The International Journal of Human Resource Management 24(1): 152-166.

Huselid, M.A. 1995. The impact of human resource management practices on turnover, productivity and corporate financial performance. Academy of Management Journal 38(3): 635-672.

Hussain, M., R.N. Malik, A. Taylor and M. Puettmann. 2017. Hazardous pollutants emissions and environmental impacts from fuelwood burned and synthetic fertilizers applied by tobacco growers in Pakistan. Environmental Technology \& Innovation 7: 169-181.

Jackson, S.E., D.W. Renwick, C.J. Jabbour and M. Muller-Camen. 2011. State-of-the-art and future directions for green human resource management: introduction to the special issue. German Journal of Human Resource Management 25(2): 99-116.

Jia, J., H. Liu, T. Chin and D. Hu. 2018. The continuous mediating effects of GHRM on employees' green passion via transformational leadership and green creativity. Sustainability 10(9): 3237.

Jiang, K., D.P. Lepak, J. Hu and J.C. Baer. 2012. How does human resource management influence organizational outcomes? A meta-analytic investigation of mediating mechanisms. Academy of management Journal 55(6): 1264-1294.

Jiang, K. and P. Li. 2019. Models of strategic human resource management. Sage handbook of human resource management. SAGE Publications Ltd., Thousand Oaks, CA, USA, pp. 23-40.

Jussila, I., A. Tarkiainen, M. Sarstedt and J.F. Hair. 2015. Individual psychological ownership: concepts, evidence, and implications for research in marketing. Journal of Marketing Theory and Practice 23(2): 121-139.

Kamleitner, B. and A. Rabinovich. 2010. Mine versus ours: does it matter? In: M.C. Campbell, J. Inman and R. Pieters (eds.) NA-advances in consumer research. Vol. 37. Association for Consumer Research, Duluth, MN, USA, pp. 828-829. 
Kassir, L.N., B. Lartiges and N. Ouaini. 2012. Effects of fertilizer industry emissions on local soil contamination: a case study of a phosphate plant on the east Mediterranean coast. Environmental Technology 33(8): 873-885.

Kim, M. and T.A. Beehr. 2017. Self-efficacy and psychological ownership mediate the effects of empowering leadership on both good and bad employee behaviors. Journal of Leadership \& Organizational Studies 24(4): 466-478.

Li, H.-W., N. Afshar-Mohajer, C.-Y. Wu, J.-C.J. Bonzongo, V.A. Ilacqua, Y. Choi and B. Birky. 2015. Impacts of hazardous air pollutants emitted from phosphate fertilizer production plants on their ambient concentration levels in the Tampa Bay area. Air Quality, Atmosphere \& Health 8(5): 453-467.

Liu, J., H. Wang, C. Hui and C. Lee. 2012. Psychological ownership: how having control matters. Journal of Management Studies 49(5): 869-895.

Lu, L., J. Liu and N. Zhao. 2017. Why employees stay: the roles of psychological ownership, territoriality and work relationship closeness in affecting employee turnover intention. Frontiers of Business Research in China 11(1): 10.

Matilainen, A., M. Pohja-Mykrä, M. Lähdesmäki and S. Kurki. 2017. 'I feel it is mine!' - psychological ownership in relation to natural resources. Journal of Environmental Psychology 51: 31-45.

Mattioda, R.A., P.T. Fernandes, J.L. Casela and O.C. Junior. 2017. Social life cycle assessment of hydrogen energy technologies. In: A. Scipioni, A. Manzardo and J. Ren (eds.) Hydrogen economy. Academic Press, Cambridge, MA, USA, pp. 171-188.

Memon, M.A., J. Cheah, T. Ramayah, H. Ting and F. Chuah. 2018. Mediation analysis issues and recommendations. Journal of Applied Structural Equation Modeling 2(1): 1-9.

Milkovich, G.T. and A.K. Wigdor. 1991. Pay for performance: evaluating performance appraisal and merit pay. National Academy Press, Washington, DC, USA.

Moise, M.S., I. Gil-Saura, M. Šerić and M.E.R. Molina. 2019. Influence of environmental practices on brand equity, satisfaction and word of mouth. Journal of Brand Management 26(6): 646-657.

Mustafa, M., H.M. Ramos and T.W.Y. Man. 2015. Linking psychological ownership to employee extra-role behaviours in small overseas Chinese family businesses. Journal of Entrepreneurship in Emerging Economies 7(2): 129-147.

Newman, C., S. Singhal and F. Tarp. 2020. Introduction to understanding agricultural development and change: learning from Vietnam. Food Policy 94: 101930.

Owino, W.A. and J. Kwasira. 2016. Influence of selected green human resource management practices on environmental sustainability at Menengai Oil Refinery Limited Nakuru, Kenya. Journal of Human Resource Management 4(3): 19-27.

Paillé, P., Y. Chen, O. Boiral and J. Jin. 2014. The impact of human resource management on environmental performance: an employee-level study. Journal of Business Ethics 121(3): 451-466.

Pham, N.T., Z. Tučková and C.J.C. Jabbour. 2019. Greening the hospitality industry: how do green human resource management practices influence organizational citizenship behavior in hotels? A mixedmethods study. Tourism Management 72: 386-399.

Pierce, J.L., T. Kostova and K.T. Dirks. 2001. Toward a theory of psychological ownership in organizations. Academy of Management Review 26(2): 298-310.

Pierce, J.L., T. Kostova and K.T. Dirks. 2003. The state of psychological ownership: integrating and extending a century of research. Review of General Psychology 7(1): 84-107.

Pierce, J.L., S.A. Rubenfeld and S. Morgan. 1991. Employee ownership: a conceptual model of process and effects. Academy of Management Review 16(1): 121-144.

Pinzone, M., M. Guerci, E. Lettieri and T. Redman. 2016. Progressing in the change journey towards sustainability in healthcare: the role of 'Green' HRM. Journal of Cleaner Production 122: 201-211.

Pittino, D., A.B. Martínez, F. Chirico and R.S. Galván. 2018. Psychological ownership, knowledge sharing and entrepreneurial orientation in family firms: the moderating role of governance heterogeneity. Journal of Business Research 84: 312-326.

Podsakoff, P.M., S.B. MacKenzie, J.-Y. Lee and N.P. Podsakoff. 2003. Common method biases in behavioral research: a critical review of the literature and recommended remedies. Journal of Applied Psychology 88(5): 879 . 
Poutsma, E., C. Van Eert and P.E. Ligthart. 2015. Employee ownership and organizational citizenship behavior: high performance ownership systems and the mediating role of psychological ownership. In: W.G. Castellano (ed.) Advances in the economic analysis of participatory \& labor-managed firms. Emerald Group Publishing Limited, Bingley, UK.

Preacher, K.J. and A.F. Hayes. 2004. SPSS and SAS procedures for estimating indirect effects in simple mediation models. Behavior Research Methods, Instruments, \& Computers 36(4): 717-731.

Presbitero, A. 2017. How do changes in human resource management practices influence employee engagement? A longitudinal study in a hotel chain in the Philippines. Journal of Human Resources in Hospitality \& Tourism 16(1): 56-70.

Rahman, K. and D. Zhang. 2018. Effects of fertilizer broadcasting on the excessive use of inorganic fertilizers and environmental sustainability. Sustainability 10(3): 759.

Ramayah, T., J. Cheah, F. Chuah, H. Ting and M. Memon. 2018. Partial least squares structural equation modeling (PLS-SEM) using smartPLS 3.0. An updated guide and practical guide to statistical analysis. Pearson Malaysia Sdn, Kuala Lumpur, Malaysia.

Rehman, A., A.A. Chandio, I. Hussain and L. Jingdong. 2017. Is credit the devil in the agriculture? The role of credit in Pakistan's agricultural sector. The Journal of Finance and Data Science 3(1-4): 38-44.

Renwick, D.W., T. Redman and S. Maguire. 2013. Green human resource management: a review and research agenda. International Journal of Management Reviews 15(1): 1-14.

Russell, A., T. Ekvall and H. Baumann. 2005. Life cycle assessment introduction and overview. Journal of Cleaner Production 13(13-14): 1207-1210.

Saeed, B.B., B. Afsar, S. Hafeez, I. Khan, M. Tahir and M.A. Afridi. 2019. Promoting employee's proenvironmental behavior through green human resource management practices. Corporate Social Responsibility and Environmental Management 26(2): 424-438.

Salem, M.A., N. Hasnan and N.H. Osman. 2012. Environmental issues and corporate performance: a critical review. Journal of Environmental \& Earth Sciences 2: 112-122.

Shafaei, A., M. Nejati and Y.M. Yusoff. 2020. Green human resource management: a two-study investigation of antecedents and outcomes. International Journal of Manpower 41(7): 1041-1060.

Singh, S.K., M. Del Giudice, R. Chierici and D. Graziano. 2020. Green innovation and environmental performance: the role of green transformational leadership and green human resource management. Technological Forecasting and Social Change 150: 119762.

Sinkovics, R.R., N.F. Richter, C.M. Ringle and C. Schlaegel. 2016. A critical look at the use of SEM in international business research. International Marketing Review 33(3): 376-404.

Struik, P.C. and T.W. Kuyper. 2017. Sustainable intensification in agriculture: the richer shade of green. A review. Agronomy for Sustainable Development 37(5): 39.

Süssenbach, S. and B. Kamleitner. 2018. Psychological ownership as a facilitator of sustainable behaviors. In: J. Peck and S.B. Shu (eds.) Psychological ownership and consumer behavior. Springer, Berlin, Germany, pp. 211-225.

Tang, G., Y. Chen, Y. Jiang, P. Paille and J. Jia. 2018. Green human resource management practices: scale development and validity. Asia Pacific Journal of Human Resources 56(1): 31-55.

Teixeira, A.A., C.J.C. Jabbour and A.B.L. De Sousa Jabbour. 2012. Relationship between green management and environmental training in companies located in Brazil: a theoretical framework and case studies. International Journal of Production Economics 140(1): 318-329.

Thore, S. and R. Tarverdyan. 2016. The sustainable competitiveness of nations. Technological Forecasting and Social Change 106: 108-114.

Tripathi, A. and A.K. Mishra. 2017. Knowledge and passive adaptation to climate change: an example from Indian farmers. Climate Risk Management 16: 195-207.

Ullah, A., D. Khan, I. Khan and S. Zheng. 2018. Does agricultural ecosystem cause environmental pollution in Pakistan? Promise and menace. Environmental Science and Pollution Research 25(14): 13938-13955.

Unsworth, K.L., A. Dmitrieva and E. Adriasola. 2013. Changing behaviour: increasing the effectiveness of workplace interventions in creating pro-environmental behaviour change. Journal of Organizational Behavior 34(2): 211-229. 
Van Dyne, L. and J.L. Pierce. 2004. Psychological ownership and feelings of possession: three field studies predicting employee attitudes and organizational citizenship behavior. Journal of Organizational Behavior: The International Journal of Industrial, Occupational and Organizational Psychology and Behavior 25(4): 439-459.

Vidal-Salazar, M.D., E. Cordón-Pozo and V. Ferrón-Vilchez. 2012. Human resource management and developing proactive environmental strategies: the influence of environmental training and organizational learning. Human Resource Management 51(6): 905-934.

Wang, L., K.S. Law, M.J. Zhang, Y.N. Li and Y. Liang. 2019. It's mine! Psychological ownership of one's job explains positive and negative workplace outcomes of job engagement. Journal of Applied Psychology 104(2): 229.

Xu, P., Y. Zhang, W. Gong, X. Hou, C. Kroeze, W. Gao and S. Luan. 2015. An inventory of the emission of ammonia from agricultural fertilizer application in China for 2010 and its high-resolution spatial distribution. Atmospheric Environment 115: 141-148.

Yong, J.Y., M.Y. Yusliza, T. Ramayah, C.J. Chiappetta Jabbour, S. Sehnem and V. Mani. 2020. Pathways towards sustainability in manufacturing organizations: empirical evidence on the role of green human resource management. Business Strategy and the Environment 29(1): 212-228.

Yu, W., R. Chavez, M. Feng, C.Y. Wong and B. Fynes. 2020. Green human resource management and environmental cooperation: an ability-motivation-opportunity and contingency perspective. International Journal of Production Economics 219: 224-235.

Zhang, T., M.J. Wooster, D.C. Green and B. Main. 2015. New field-based agricultural biomass burning trace gas, PM2. 5, and black carbon emission ratios and factors measured in situ at crop residue fires in Eastern China. Atmospheric Environment 121: 22-34. 
